\title{
Efficacy of lipid lowering drug treatment for diabetic and non-diabetic patients: meta-analysis of randomised controlled trials
}

\author{
João Costa, Margarida Borges, Cláudio David, António Vaz Carneiro
}

\begin{abstract}
Objective To evaluate the clinical benefit of lipid lowering drug treatment in patients with and without diabetes mellitus, for primary and secondary prevention.

Design Systematic review and meta-analysis.

Data sources Cochrane, Medline, Embase, and reference lists up to April 2004.

Study selection Randomised, placebo controlled, double blind trials with a follow-up of at least three years that evaluated lipid lowering drug treatment in patients with and without diabetes mellitus.

Data extraction Two independent reviewers extracted data. The primary outcome was major coronary events defined as coronary heart disease death, non-fatal myocardial infarction, or myocardial revascularisation procedures.

Results Twelve studies were included. Lipid lowering drug treatment was found to be at least as effective in diabetic patients as in non-diabetic patients. In primary prevention, the risk reduction for major coronary events was 21\% (95\% confidence interval $11 \%$ to $30 \% ; \mathrm{P}<0.0001$ ) in diabetic patients and $23 \%(12 \%$ to $33 \% ; \mathrm{P}=0.0003)$ in non-diabetic patients. In secondary prevention, the corresponding risk reductions were $21 \%(10 \%$ to $31 \% ; \mathrm{P}=0.0005)$ and $23 \%(19 \%$ to $26 \%$; $\mathrm{P} \leq 0.00001)$. However, the absolute risk difference was three times higher in secondary prevention. When results were adjusted for baseline risk, diabetic patients benefited more in both primary and secondary prevention. Blood lipids were reduced to a similar degree in both groups.

Conclusions The evidence that lipid lowering drug treatment (especially statins) significantly reduce cardiovascular risk in diabetic and non-diabetic patients is strong and suggests that diabetic patients benefit more, in both primary and secondary prevention. Future research should define the threshold for treatment of these patients and the desired target lipid concentrations, especially for primary prevention.
\end{abstract}

\section{Introduction}

The prevalence of diabetes mellitus is increasing. Up to 218 million people are likely to have the disease by $2010 .^{1}$ The current understanding is that type 2 diabetes mellitus is a metabolic disorder, defined by hyperglycaemia, with dyslipidaemia, hypertension, abdominal obesity, and insulin resistance. The management of diabetes mellitus has changed recently, from a focus on hyperglycaemia alone to a multifactorial approach to risk management. $^{1}$

The risk of myocardial infarction in patients with diabetes mellitus without a history of myocardial infarction is as high as that in patients without diabetes mellitus who have had a myocardial infarction. ${ }^{2}$ Mortality after the first myocardial infarction is higher in both men and women with diabetes mellitus than in their non-diabetic counterparts. ${ }^{3}$ US epidemiological data show that although mortality due to coronary artery disease has declined overall, this is not the case in the diabetic population. In the UK prospective diabetes study, ${ }^{4} 49 \%$ of deaths within 10 years of diagnosis were due to cardiovascular disease. In addition, atherosclerosis is more frequent and more extensive and has an earlier onset among people with diabetes mellitus than in people without the condition.

Diabetes affects virtually all lipids and lipoproteins, and dyslipidaemia is a consistent finding in people with type 2 diabetes. Patients typically have increased plasma concentrations of triglycerides, low plasma concentrations of high density lipoprotein (HDL) cholesterol, but only slightly raised plasma concentrations of low density lipoprotein (LDL) cholesterol. Patients with type 2 diabetes also tend to have a preponderance of atherogenic small dense LDL. ${ }^{5-8}$ In one study, $79 \%$ of patients were classified as having small dense LDL (apolipoprotein B in LDL-5 plus LDL-6 $>25 \mathrm{mg} / \mathrm{dl}) .^{9}$

The effectiveness of 3-hydroxy-3-methylglutaryl coenzyme A reductase inhibitors (statins) in treating dyslipidaemia, and thereby reducing the risk of coronary events, has been shown in large scale studies of both primary and secondary intervention to reduce coronary artery disease. ${ }^{10}$ The results of the heart protection study did not show a threshold effect in benefit associated with reduction in LDL cholesterol, ${ }^{11}$ suggesting that the use of the classic target concentration to guide treatment may result in undertreatment of many patients who would benefit from additional lowering of LDL cholesterol. The National Cholesterol Education Program Adult Treatment Panel III guidelines include diabetes mellitus in the newly defined coronary artery disease risk equivalent category, carrying the recommendation of lipid lowering treatment to reduce LDL cholesterol to a target of $<100 \mathrm{mg} / \mathrm{dl}^{12}$

A recent meta-analysis has evaluated the efficacy of lipid lowering drug treatment in patients with type 2 diabetes on the basis of subgroup analysis from large trials and showed that both statins and fibrates reduce the cardiovascular risk. ${ }^{13}$ These data served as a basis for the background paper that the American College of Physicians used to support the recent guidelines for lipid control in the management of type 2 diabetes. ${ }^{14}$ The main practice recommendations were that lipid lowering drug treatment should be used for secondary prevention of cardiovascular mortality and morbidity in all patients (both men and women) with known coronary artery disease and type 2 diabetes and that statins should be used for primary prevention against 
macrovascular complications in patients (both men and women) with type 2 diabetes and other cardiovascular risk factors.

Bearing in mind the limitations of this meta-analysis (search date, number of included trials, outcomes selected, and data for non-diabetic patients), we aimed to evaluate and compare the efficacy of lipid lowering drug treatment in patients with and without diabetes mellitus, by doing a meta-analysis of published unconfounded randomised, prospective, placebo controlled, double blind clinical trials.

\section{Methods}

\section{Studies}

The criteria for inclusion of trials in the meta-analysis were a lipid lowering/cholesterol drug arm; a placebo arm; adequate concealment of random allocation; double blind assessment, including clinical outcomes; at least 500 patients per group; reference to type 2 diabetic patients and non-diabetic patients in both arms; follow-up of at least three years; a hard end point that was a cardiovascular event as the primary or secondary end point; and provision for or allowing calculation of individual results for the diabetic and non-diabetic subgroups.

We considered trials that enrolled patients with or without previous coronary artery disease, aiming to evaluate the efficacy in both primary and secondary prevention. We excluded trials that followed patients for a short period of time, mainly because cardiovascular risk falls relatively little within the first two years before the full effect of reducing serum LDL cholesterol concentrations is achieved, ${ }^{15}$ thereby underestimating the preventive effect of lipid lowering drug treatment. ${ }^{16}$

\section{Outcome measures}

Our primary outcome was a composite of major coronary events defined as coronary artery disease death, non-fatal myocardial infarction, or myocardial revascularisation procedures (coronary artery bypass grafting or percutaneous transluminal coronary angioplasty). Secondary outcomes were coronary artery disease death or non-fatal myocardial infarction, coronary artery disease death, non-fatal myocardial infarction, revascularisation procedures, stroke, and blood lipid concentration changes: total cholesterol, LDL cholesterol, HDL cholesterol, and triglycerides.

\section{Search strategy for identification of studies}

We identified published studies through a literature search using Medline (1966 through April 2004), Embase (1980 through April 2004), and Cochrane Central (in Cochrane Library issue 2, 2004) and by extensive searching using cross references from original articles and reviews.

The search of the electronic databases used the following terms: exp "antilipemic agents"/; lovastatin; simvastatin; fluvastatin; pravastatin; cerivastatin; atorvastatin; rosuvastatin; bezafibrate; colestipol; gemfibrozil; procetofen; or nicotinic acid. We searched all terms as indexed and as free text terms. Additionally, we used the conditions (exp "diabetes mellitus"/or diabet*.tw) and (exp "cardiovascular diseases"/or "cerebrovascular disorders"/; or "mortality"/or "myocardial revascularization"/) to identify trials that included diabetic patients and measured cardiac or cerebrovascular outcomes. We limited the search to English language papers and to humans. We screened titles, keywords, and abstracts of the citations downloaded from the electronic searches and obtained full copies of potentially suitable reports for further assessment.

\section{Study selection and data extraction}

Two authors (JC, MB) independently assessed the studies identified by the search strategy, to identify potentially suitable trials according to the criteria outlined above. Details about methodological quality and sources of bias, demographics, and clinical characteristics, number of patients excluded or lost to follow-up, definition of outcomes, entry and exclusion criteria, and extraction of eligible data were obtained independently, written on to standardised forms, and cross checked for accuracy. All disagreements were resolved by consensus.

\section{Data analyses}

We used the statistical software provided by the Cochrane Collaboration (Revman 4.2.7) for statistical analyses. We tested heterogeneity between trial results by using the $I^{2}$ test. We reported the results as relative risk reduction (and 95\% confidence intervals), using the DerSimonian and Laird random effect method or the Mantel-Hansel fixed effect method, according to the existence or not of important heterogeneity between trial results.

We compared the significance of any differences between subgroups by calculating a two tailed $\mathrm{z}$ score $(\mathrm{z}=(\operatorname{lnOR} 1-\ln \mathrm{OR} 2) / \sqrt{ }(\operatorname{var}[\operatorname{lnOR} 1]+\operatorname{var}[\operatorname{lnOR} 2])$, where OR 1 and OR2 are the combined odds ratios from each subgroup and var is the variance of each determined from the $95 \%$ confidence interval) ${ }^{17}$ We also used the standard $\chi^{2}$ test for heterogeneity. ${ }^{18}$

We calculated the number needed to treat and $95 \%$ confidence interval from meta-analysis estimates (adjusted odds ratio) and did not treat the data as if they all arose from a single trial, as this approach is more prone to bias, especially when important imbalances exist between groups within one or more trials in the meta-analysis. ${ }^{19}$ Calculations also took into account the baseline risk, defined as the percentage of patients with events in the control arm.

Analysis was done separately for primary and secondary prevention, for diabetic and non-diabetic patients, and for statins and fibrates.

\section{Results}

\section{Description of studies}

The search yielded a total of 581 reports. Applying our criteria, we selected 12 trials for inclusion in the final analysis; six trials reported data on primary coronary artery disease prevention, and eight reported on secondary prevention. ${ }^{11}{ }^{20-37}$ Table 1 shows the main characteristics of these studies.

We excluded two important trials (WOSCOPS and BIP) because no data were available for diabetic patients. WOSCOPS was a primary prevention trial of pravastatin versus placebo that enrolled 6595 male patients with hypercholesterolaemia, of whom only $1 \%$ had diabetes. ${ }^{38}{ }^{39}$ The relative risk reduction of coronary events was 31\% (95\% confidence interval $17 \%$ to $43 \%)$. BIP was a secondary prevention trial of bezafibrate versus placebo that enrolled 3090 patients, of whom only 10\% had diabetes. ${ }^{40}$ No significant differences were found.

\section{Event rate}

As expected, diabetic patients had a significantly higher risk of major coronary events than non-diabetic patients, in both placebo and treatment groups, in primary and secondary prevention trials (fig 1 and fig 2).

\section{Clinical outcomes}

Lipid lowering drug treatment seems to be equally efficacious in diabetic and non-diabetic patients. In primary prevention, the risk reduction for a major coronary event was $21 \%(11 \%$ to $30 \%$; $\mathrm{P}<0.0001)$ in diabetic patients and $23 \%(12 \%$ to $33 \%$; $\mathrm{P}=0.0003$ ) in non-diabetic patients treated with either statins or 
Table 1 Characteristics of included studies

\begin{tabular}{|c|c|c|c|c|c|c|c|c|c|c|c|}
\hline Trial & $\begin{array}{l}\text { Type of } \\
\text { prevention }\end{array}$ & Patients & Drug & No & $\begin{array}{c}\text { Mean (range) } \\
\text { age }\end{array}$ & $\begin{array}{c}\text { Women } \\
(\%)\end{array}$ & $\begin{array}{l}\text { DM } \\
(\%)\end{array}$ & $\begin{array}{l}\text { Mean } \\
\text { baseline } \\
\text { total-C } \\
(\mathrm{mmol} / \mathrm{l})\end{array}$ & $\begin{array}{c}\text { Mean } \\
\text { follow-up } \\
\text { (years) }\end{array}$ & $\begin{array}{l}\text { Primary } \\
\text { outcome }\end{array}$ & $\begin{array}{l}\text { Quality } \\
\text { appraisal } \\
\text { (Jadad } \\
\text { scale) }\end{array}$ \\
\hline $\begin{array}{l}\text { AFCAPS/ } \\
\text { TexCAPS }^{20}\end{array}$ & Primary & $\begin{array}{l}22 \% \text { HT; } 13 \% \\
\text { smoking; } 35 \% \text { low } \\
\text { HDL-C }\end{array}$ & $\begin{array}{l}\text { Lovastatin } 20 \\
\mathrm{mg} / \mathrm{day} \text {, titrated to } \\
40 \mathrm{mg} / \mathrm{day} \text { if } \\
\mathrm{LDL}-\mathrm{C}>2.84 \\
\mathrm{mmol} / / \mathrm{l}\end{array}$ & 6605 & 58 (45-73) & 15 & 2.3 & 5.7 & 5.2 & $\begin{array}{l}\text { Fatal or non-fatal } \\
\text { Ml, unstable } \\
\text { angina, or } \\
\text { sudden cardiac } \\
\text { death }\end{array}$ & 5 \\
\hline ALLHAT-LLA ${ }^{21}$ & Primary & $\begin{array}{l}\text { HT plus one other } \\
\text { CHD risk factor; } 13 \% \\
\text { had } \mathrm{CHD}\end{array}$ & $\begin{array}{l}\text { Pravastatin } 40 \\
\mathrm{mg} / \text { day } v \text { usual } \\
\text { care rather than } \\
\text { placebo }\end{array}$ & 10355 & $\begin{array}{l}66(55-?) \\
(55 \% \geq 65)\end{array}$ & 49 & 35 & 5.8 & 4.8 & $\begin{array}{l}\text { All cause } \\
\text { mortality }\end{array}$ & 3 \\
\hline $\mathrm{HHS}^{22}$ & Primary & $\begin{array}{l}\text { Primary dyslipidaemia } \\
\text { (non-HDL-C >5.2 } \\
\mathrm{mmol} / \mathrm{l} \text { ) }\end{array}$ & $\begin{array}{l}\text { Gemfibrozil } 600 \\
\text { mg twice a day }\end{array}$ & 4081 & 47 (40-55) & 0 & 3.3 & $6.3^{*}$ & 5.0 & $\begin{array}{l}\text { CHD death or MI } \\
\text { (fatal or } \\
\text { non-fatal) }\end{array}$ & 5 \\
\hline ASCOT-LLA ${ }^{23}$ & Primary & $\begin{array}{l}\text { HT plus three other } \\
\text { cardiovascular risk } \\
\text { factors }\end{array}$ & $\begin{array}{l}\text { Atorvastatin } 10 \\
\mathrm{mg} / \text { day }\end{array}$ & 10305 & 63 (40-79) & 19 & 24.6 & 5.5 & $3.3^{* *}$ & $\begin{array}{l}\text { CHD death or } \\
\text { non-fatal MI }\end{array}$ & 5 \\
\hline $\mathrm{HPS}^{11,24}$ & $\begin{array}{l}\text { Primary and } \\
\text { secondary }\end{array}$ & $\begin{array}{l}65 \% \text { CHD; } 35 \% \text { CVD, } \\
\text { PAD, or DM }\end{array}$ & $\begin{array}{l}\text { Simvastatin } 40 \\
\mathrm{mg} / \text { day }\end{array}$ & 20536 & $64(40-80)$ & 25 & 29 & 5.9 & 5.0 & $\begin{array}{l}\text { All cause } \\
\text { mortality }\end{array}$ & 5 \\
\hline PROSPER $^{25}$ & $\begin{array}{l}\text { Primary and } \\
\text { secondary }\end{array}$ & $\begin{array}{l}44 \% \text { vascular disease } \\
\text { (CHD, CVD, PAD); } \\
56 \% \text { HT, DM, or } \\
\text { smoking }\end{array}$ & $\begin{array}{l}\text { Pravastatin } 40 \\
\mathrm{mg} / \text { day }\end{array}$ & 5804 & 75 (70-82) & 52 & 10.7 & 5.7 & 3.2 & $\begin{array}{l}\text { CHD death or } \\
\text { non-fatal MI or } \\
\text { stroke (fatal and } \\
\text { non-fatal) }\end{array}$ & 5 \\
\hline $4 \mathrm{~S}^{26-28}$ & Secondary & $\begin{array}{l}\text { MI }(80 \%) \text { or angina } \\
\text { pectoris }\end{array}$ & $\begin{array}{l}\text { Simvastatin } 20 \\
\mathrm{mg} / \text { day, titrated to } \\
40 \mathrm{mg} / \text { day if total } \\
\text { cholesterol }>5.17 \\
\mathrm{mmol} / /\end{array}$ & 4444 & $59(35-70)$ & 19 & 10.8 & 6.8 & $5.4^{\star \star *}$ & $\begin{array}{l}\text { All cause } \\
\text { mortality }\end{array}$ & 5 \\
\hline CARE $^{29,30}$ & Secondary & $\mathrm{Ml}$ & $\begin{array}{l}\text { Pravastatin } 40 \\
\mathrm{mg} / \text { day; } \\
\text { cholestyramine } \\
\text { added if } \mathrm{LDL}-\mathrm{C} \\
>4.53 \mathrm{mmol} / \mathrm{l}\end{array}$ & 4159 & 59 (21-75) & 14 & 14.1 & 5.4 & $5.0^{* \star}$ & $\begin{array}{l}\mathrm{CHD} \text { death or } \\
\text { non-fatal } \mathrm{MI}\end{array}$ & 4 \\
\hline $\mathrm{LIPID}^{31,32}$ & Secondary & $\begin{array}{l}\mathrm{MI}(64 \%) \text { or } \\
\text { unstable angina }\end{array}$ & $\begin{array}{l}\text { Pravastatin } 40 \\
\text { mg/day }\end{array}$ & 9014 & 62 (31-75) & 17 & 12.1 & 5.6 & 6.1 & CHD death & 5 \\
\hline $\mathrm{LIPS}^{33}$ & Secondary & Successful PCl & $\begin{array}{l}\text { Fluvastatin } 40 \mathrm{mg} \\
\text { twice a day }\end{array}$ & 1677 & $60(18-80)$ & 16 & 12 & 5.2 & $3.9^{* *}$ & $\begin{array}{l}\text { CHD death, } \\
\text { non-fatal MI, or } \\
\text { reintervention } \\
\text { procedure }\end{array}$ & 5 \\
\hline Post-CABG ${ }^{34,35}$ & Secondary & $\begin{array}{l}\text { Coronary bypass } \\
\text { grafts; } 49 \% \text { had } \mathrm{Ml}\end{array}$ & $\begin{array}{l}\text { LDL-C goal of } \\
1.55-2.20 \mathrm{mmol} / \mathrm{l} \mathrm{v} \\
3.36-3.62 \mathrm{mmol} / \mathrm{l} \\
\text { using lovastatin } \\
\end{array}$ & 1351 & $62(21-74)$ & 7.8 & 8.6 & 5.9 & 4.3 & $\begin{array}{l}\text { Angiographic } \\
\text { outcomes }\end{array}$ & 3 \\
\hline VA-HIT ${ }^{36,37}$ & Secondary & $\begin{array}{l}\mathrm{Ml}(61 \%) \text {, angina, } \\
\text { coronary } \\
\text { revascularisation, or } \\
\text { angiographic stenosis } \\
>50 \%\end{array}$ & $\begin{array}{l}\text { Gemfibrozil } 600 \\
\text { mg twice a day }\end{array}$ & 2531 & $\begin{array}{l}64(?-74) \\
(77 \%>60)\end{array}$ & 0 & 30 & 4.5 & $5.1^{* *}$ & $\begin{array}{l}\text { CHD death or } \\
\text { non-fatal MI }\end{array}$ & 5 \\
\hline
\end{tabular}

$\mathrm{CHD}=$ coronary heart disease; $\mathrm{CVD}=$ cerebrovascular disease; $\mathrm{DM}=$ diabetes mellitus; HDL-C=high density lipoprotein cholesterol; LDL-C=low density lipoprotein cholesterol; total-C=total cholesterol $\mathrm{Ml}=$ myocardial infarction; $\mathrm{HT}=$ hypertension; $\mathrm{PAD}=$ peripheral arterial disease; $\mathrm{PCl}=$ percutaneous coronary intervention.

${ }^{*}$ Non-HDL-C (total cholesterol minus LDL cholesterol).

**Median.

gemfibrozil. In secondary prevention, the risk reduction for a major coronary event was $21 \%(10 \%$ to $31 \% ; \mathrm{P}=0.0005)$ in dia-

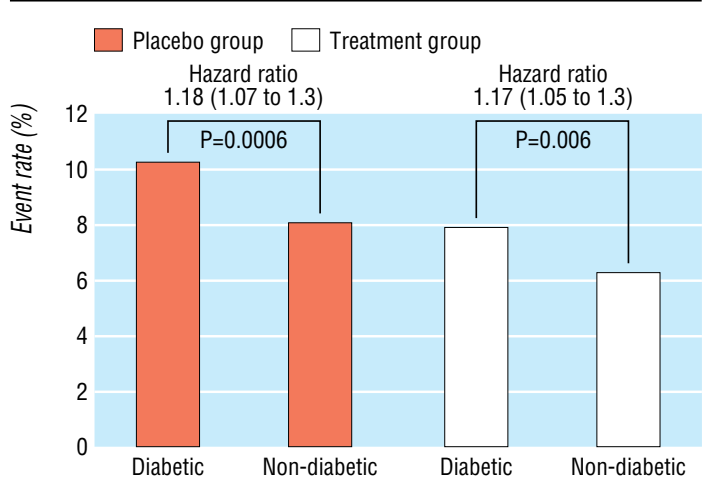

Fig 1 Event rate for major coronary events in primary prevention trials (mean weighted follow-up 4.5 years) betic patients and $23 \% \quad(19 \%$ to $26 \% ; \quad \mathrm{P}<0.00001)$ in non-diabetic patients treated with either statins or gemfibrozil.

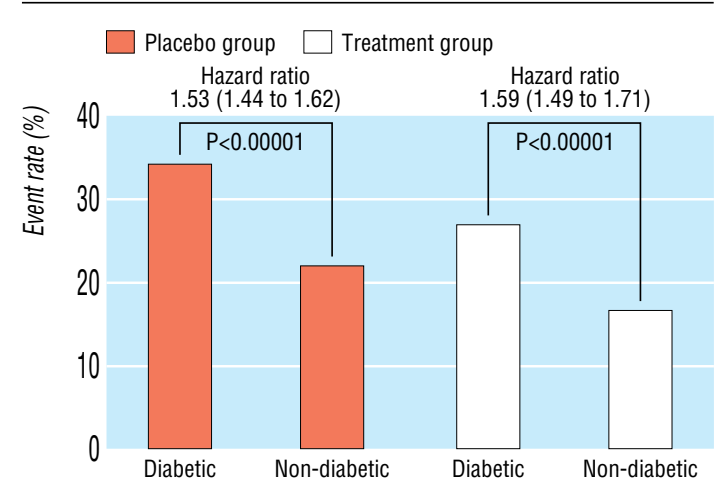

Fig 2 Event rate for major coronary events in secondary prevention trials (mean weighted follow-up 5.1 years) 


\section{Research}

Although we found similar relative risk reductions and odds ratios for the primary outcome in primary and secondary prevention, the absolute risk difference was significantly higher in secondary prevention. In primary prevention, the risk difference for major coronary events was $-0.02(-0.04$ to $-0.00 ; \mathrm{P}=0.1)$ in diabetic patients and $-0.02(-0.02$ to -0.01 ; $\mathrm{P}<0.00001$ ) in non-diabetic patients (fig 3). In secondary prevention, the risk difference for major coronary events was $-0.07(-0.11$ to $-0.03 ; \mathrm{P}=0.0003)$ in diabetic patients and -0.05 ( -0.06 to $-0.04 ; \mathrm{P}<0.00001)$ in non-diabetic patients (fig 4).

In secondary prevention, we found important differences in secondary outcomes between diabetic and non-diabetic patients. The risk reduction in diabetic and non-diabetic patients treated with either statins or gemfibrozil was $22 \%(9 \%$ to $34 \% ; \mathrm{P}=0.001)$ and $26 \%(22 \%$ to $30 \% ; \mathrm{P}<0.00001)$ for coronary artery disease death or non-fatal myocardial infarction; $30 \%$ (8\% to $47 \%$; $\mathrm{P}=0.01)$ and $21 \%(5 \%$ to $35 \% ; \mathrm{P}=0.01)$ for coronary artery disease death (fig 5); $39 \%$ ( $4 \%$ to $62 \% ; \mathrm{P}=0.03$ ) and $29 \%(18 \%$ to
$39 \% ; \mathrm{P}<0.00001)$ for non-fatal myocardial infarction (fig 6); $30 \% \quad(17 \%$ to $41 \% ; \mathrm{P} \leq 0.0001)$ and $23 \%(18 \%$ to $27 \%$; $\mathrm{P} \leq 0.00001$ ) for revascularisation procedures (fig 7); and $36 \%$ (17\% to $51 \% ; \mathrm{P}=0.0008)$ and $22 \%(13 \%$ to $30 \% ; \mathrm{P} \leq 0.00001)$ for stroke (fig 8).

Although the efficacy of lipid lowering drug treatment, assessed by risk reduction, was in general similar in diabetic and non-diabetic patients, when we adjusted the results for baseline risk diabetic patients benefited more than non-diabetic patients in secondary prevention for coronary artery disease death, nonfatal myocardial infarction, revascularisation, and stroke. This difference did not reach significance for primary prevention of major coronary events. Table 2 shows the number needed to treat and the benefit per 1000 patients treated.

For some outcomes we found significant heterogeneity $\left(I^{2}>50 \%\right)$ between study results. This was the case for primary prevention of major coronary events in non-diabetic patients $\left(I^{2}=68 \%\right)$-the funnel plot showed that this was because of the results of the ALLHAT-LLT and PROSPER studies-and in sec-

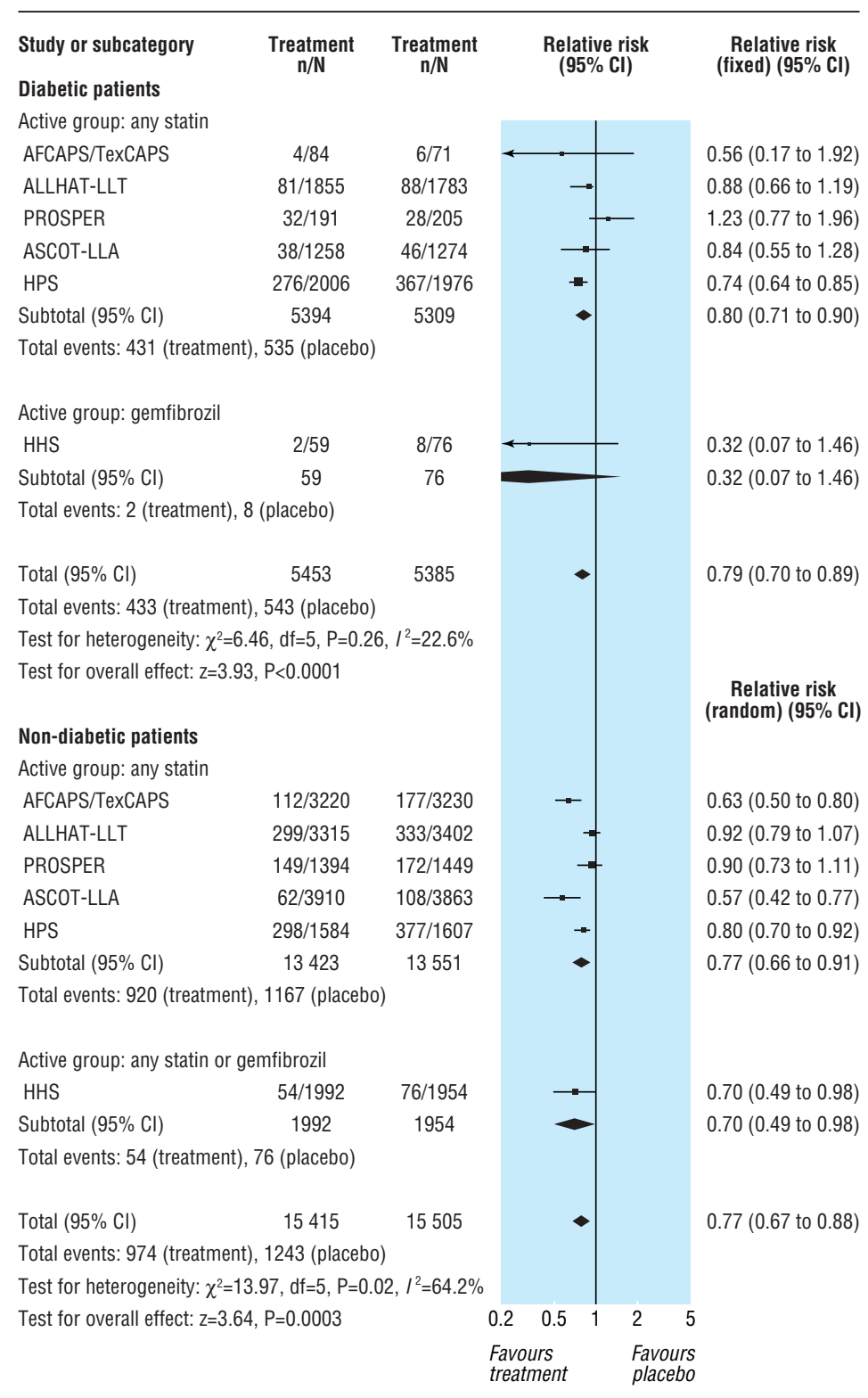

Fig 3 Primary prevention of major coronary events 
ondary prevention of major coronary events in diabetic patients $\left(I^{2}=54 \%\right)$, owing to the results of the PROSPER study. Additionally, in secondary prevention of coronary artery disease death $\left(I^{2}=63 \%\right)$ and non-fatal myocardial infarction in non-diabetic patients $\left(I^{2}=51 \%\right)$ it was because of the results of the post-CABG study, and in secondary prevention of non-fatal myocardial infarction in diabetic patients $\left(I^{2}=54 \%\right)$ it was owing to the results of the CARE study (see figures 3 to 6 for individual study results). As we have taken trials' heterogeneity into account in the analysis, our results probably underestimate the true magnitude of the treatment effect.

\section{Effects on blood lipids}

The magnitude of change in blood lipids was similar in diabetic and non-diabetic groups; most trials showed a decrease of
$15-20 \%$ in total cholesterol and increases of 5-7.5\% in HDL cholesterol (fig 9). Trials that used gemfibrozil (VA-HIT and HHS) showed smaller decreases in total cholesterol and LDL cholesterol. In the VA-HIT trial, no changes in LDL cholesterol were detected in either group.

\section{Discussion}

High blood cholesterol has been shown to be a risk factor for cardiovascular death and coronary heart disease in patients with or without a history of coronary artery disease. ${ }^{41}{ }^{42}$ As the relation between blood cholesterol and cardiovascular risk is continuous $^{43}$ (although it can be J shaped for total mortality in some studies), no definite threshold exists above which patients must be treated. In fact, the decision to treat depends more on

\begin{tabular}{|c|c|c|c|c|c|}
\hline Study or subcategory & $\underset{n / N}{\text { Treatment }}$ & $\underset{n / N}{\text { Treatment }}$ & \multirow{2}{*}{\multicolumn{2}{|c|}{$\begin{array}{l}\text { Relative risk } \\
(95 \% \mathrm{Cl})\end{array}$}} & $\begin{array}{c}\text { Relative risk } \\
\text { (random) }(95 \% \mathrm{Cl})\end{array}$ \\
\hline \multicolumn{4}{|l|}{ Diabetic patients } & & \\
\hline \multicolumn{6}{|l|}{ Active group: any statin } \\
\hline CARE & $81 / 282$ & $112 / 304$ & $\rightarrow$ & & 0.78 (0.62 to 0.99$)$ \\
\hline $4 S$ & $59 / 251$ & $87 / 232$ & $\rightarrow$ & & $0.63(0.47$ to 0.83$)$ \\
\hline Post-CABG & $9 / 63$ & $14 / 53$ & & & $0.54(0.25$ to 1.15$)$ \\
\hline LIPS & $26 / 120$ & $31 / 82$ & $\longrightarrow$ & & 0.57 (0.37 to 0.89$)$ \\
\hline PROSPER & $38 / 112$ & $31 / 115$ & & & $1.26(0.85$ to 1.87$)$ \\
\hline HPS & $325 / 972$ & $381 / 1009$ & & & $0.89(0.79$ to 1.00$)$ \\
\hline LIPID & $106 / 542$ & $125 / 535$ & $\rightarrow$ & & $0.84(0.67$ to 1.05$)$ \\
\hline Subtotal $(95 \% \mathrm{Cl})$ & 2342 & 2330 & $\bullet$ & & 0.79 (0.68 to 0.93$)$ \\
\hline \multicolumn{6}{|c|}{ Total events: 644 (treatment), 781 (placebo) } \\
\hline \multicolumn{6}{|c|}{ Active group: gemfibrozil } \\
\hline VA-HIT & $99 / 378$ & $141 / 391$ & $\rightarrow$ & & $0.73(0.59$ to 0.90$)$ \\
\hline Subtotal $(95 \% \mathrm{Cl})$ & 378 & 391 & $<$ & & $0.73(0.59$ to 0.90$)$ \\
\hline \multicolumn{6}{|c|}{ Total events: 99 (treatment), 141 (placebo) } \\
\hline Total $(95 \% \mathrm{Cl})$ & 2720 & 2721 & $\bullet$ & & $0.79(0.69$ to 0.90$)$ \\
\hline \multicolumn{6}{|c|}{ Total events: 743 (treatment), 922 (placebo) } \\
\hline \multicolumn{6}{|c|}{ Test for heterogeneity: $\chi^{2}=14.82, \mathrm{df}=7, \mathrm{P}=0.04, I^{2}=52.8 \%$} \\
\hline \multicolumn{6}{|c|}{ Test for overall effect: $z=3.48, P=0.0005$} \\
\hline \multicolumn{6}{|l|}{ Non-diabetic patients } \\
\hline \multicolumn{6}{|l|}{ Active group: any statin } \\
\hline CARE & $349 / 1774$ & $437 / 1799$ & $\rightarrow$ & & $0.81(0.72$ to 0.92$)$ \\
\hline $4 \mathrm{~S}$ & $366 / 1949$ & $530 / 1966$ & $=$ & & $0.70(0.62$ to 0.78$)$ \\
\hline Post-CABG & $77 / 613$ & $89 / 622$ & $\rightarrow$ & & $0.88(0.66$ to 1.17$)$ \\
\hline LIPS & $155 / 724$ & $191 / 751$ & $\rightarrow$ & & $0.84(0.70$ to 1.01$)$ \\
\hline PROSPER & $189 / 1194$ & $242 / 1144$ & $\rightarrow$ & & $0.75(0.63$ to 0.89$)$ \\
\hline HPS & $1134 / 5722$ & $1460 / 5683$ & - & & $0.77(0.72$ to 0.83$)$ \\
\hline LIPID & $451 / 3970$ & $590 / 3967$ & - & & $0.76(0.68$ to 0.86$)$ \\
\hline Subtotal $(95 \% \mathrm{Cl})$ & 15946 & 15932 & - & & $0.77(0.73$ to 0.80$)$ \\
\hline \multicolumn{6}{|c|}{ Total events: 2721 (treatment), 3539 (placebo) } \\
\hline \multicolumn{6}{|l|}{ Active group: gemfibrozil } \\
\hline VA-HIT & $157 / 879$ & $187 / 869$ & $\rightarrow$ & & $0.83(0.69$ to 1.00$)$ \\
\hline Subtotal $(95 \% \mathrm{Cl})$ & 879 & 869 & $\bullet$ & & $0.83(0.69$ to 1.00$)$ \\
\hline \multicolumn{6}{|c|}{ Total events: 157 (treatment), 187 (placebo) } \\
\hline Total $(95 \% \mathrm{Cl})$ & 16825 & 16801 & - & & $0.77(0.74$ to 0.81$)$ \\
\hline \multicolumn{6}{|c|}{ Total events: 2878 (treatment), 3726 (placebo) } \\
\hline \multicolumn{6}{|c|}{ Test for heterogeneity: $\chi^{2}=5.84, \mathrm{df}=7, \mathrm{P}=0.56, I^{2}=0 \%$} \\
\hline \multirow{2}{*}{\multicolumn{2}{|c|}{ Test for overall effect: $z=11.69, P<0.00001$}} & & $0.2 \quad 0.5$ & 2 & 5 \\
\hline & & & $\begin{array}{l}\text { Favours } \\
\text { treatment }\end{array}$ & & \\
\hline
\end{tabular}

Fig 4 Secondary prevention of major coronary events 
the expected absolute risk reduction, taking into account the amount of resources that can be diverted for prevention. ${ }^{44}$ Consequently, variable entry criteria are found in several clinical trials.

Cardiovascular disease is the most common cause of death in the general population. In the United Kingdom and United States, $60-70 \%$ of the population die from cardiovascular disease. In people with diabetes, cardiovascular disease complications cause even more morbidity and mortality. ${ }^{45}$ Diabetes is an independent risk factor for cardiovascular disease (up to fivefold), and as many as $80 \%$ of patients with type 2 diabetes die from cardiovascular complications, a risk that is not completely explained by traditional risk factors. ${ }^{46}$

Our meta-analysis clearly confirms that reduction of LDL cholesterol concentrations results in an important decrease in major coronary events in diabetic patients and shows similar relative risk reductions and odds ratios for our primary outcomes (major coronary events) in both diabetic and non-diabetic patients and in primary and secondary prevention. However, the absolute risk difference was three times higher in secondary prevention, reflecting the higher baseline cardiovas- cular risk of these patients, as indicated by the higher rate of coronary events in secondary prevention trials.

We were unable to analyse secondary outcomes in primary prevention, as no data were available from the trials. Also, indirect comparisons between statins and fibrates should be made with caution, as only one trial evaluated fibrate treatment. Importantly, the results of some secondary outcomes in secondary prevention clearly show that diabetic patients benefit significantly more from treatment with lipid lowering drugs than do non-diabetic patients.

\section{Limitations of the study}

Our meta-analysis has some limitations. Firstly, we included the results of the PROSPER, post-CABG, and VA-HIT studies in our primary outcome, although these studies report only combined results for coronary events and stroke. Secondly, for all our secondary outcomes we excluded the data from diabetic patients in the HPS study, because only $33 \%$ of these patients had history of coronary artery disease and no individual information was available for subgroups of diabetic patients with or without previous coronary artery disease. Thirdly, the definition of diabetes has

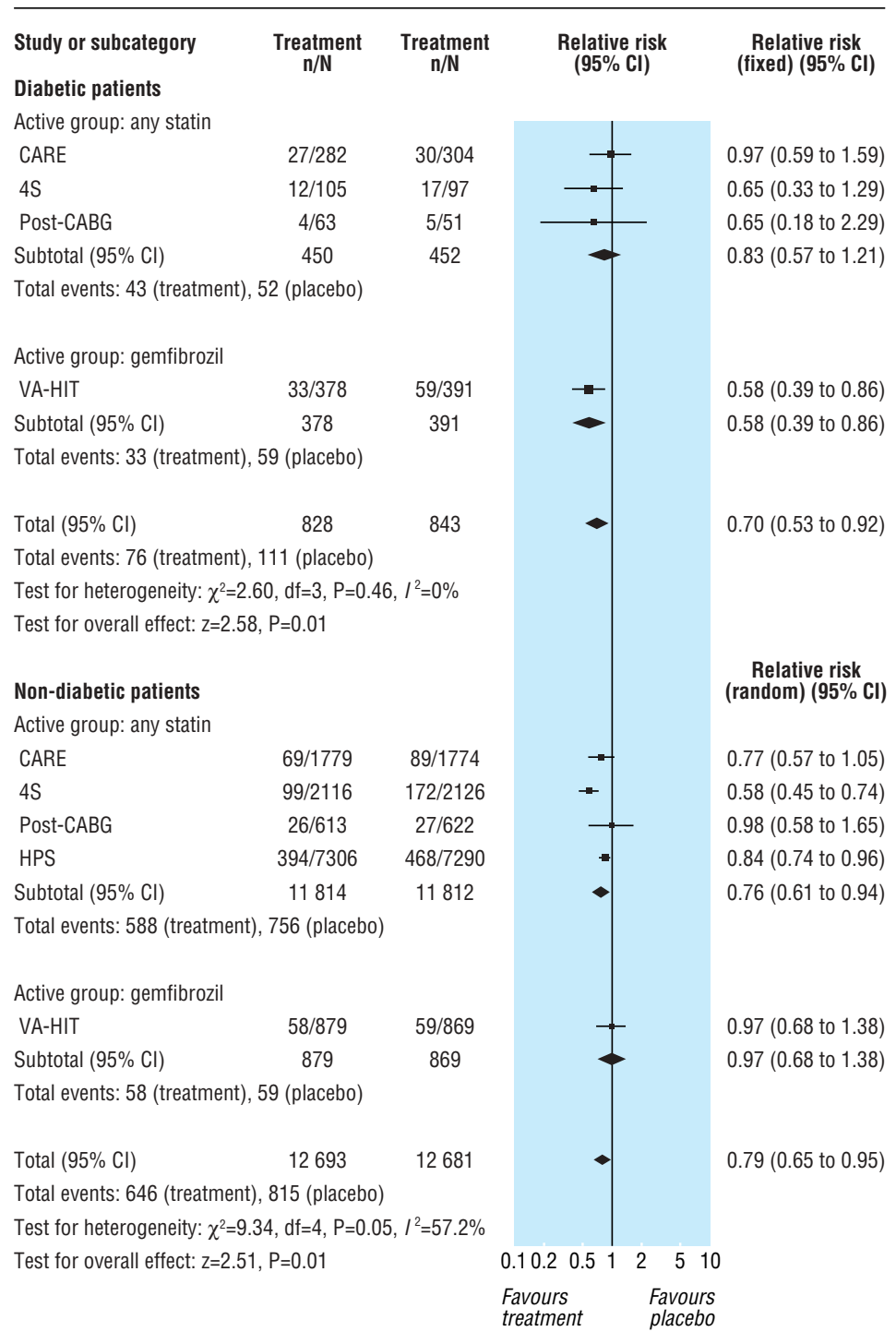

Fig 5 Secondary prevention of coronary heart disease death 
changed over the years and seven (4S, HHS, VA-HIT, post-CABG, LIPID, HPS, and CARE) of the 12 studies included have released post hoc analysis for the diabetic patients' subgroup (for the meta-analysis we considered the most updated results and not those from the original reports). Fourthly, we included the post-CABG study, which had a 2x2 factorial design and compared moderate versus aggressive treatment without a true placebo arm. Fifthly, we were unable to explore the effect of the dose or individual drugs. None the less, to our knowledge, this is the first meta-analysis that has compared cardiovascular risk reduction in diabetic versus non-diabetic patients.

\section{Implications for practice}

Although the benefits of statins for secondary prevention of coronary artery disease have been well documented, they are not being optimally used in patients at higher risk-the ones most likely to benefit. A recent cohort study of 396077 patients aged 66 years or more who had a history of cardiovascular disease or diabetes mellitus found that only $19.1 \%$ of the patients were prescribed statins. Additionally, the likelihood of statin use diminished progressively as baseline cardiovascular risk and future probability of death increased. ${ }^{47}$
The management of dyslipidaemia in adults with diabetes is receiving attention, as these patients are at higher risk of coronary artery disease and statins could have a preferential effect to decrease concentrations of atherogenic small dense LDL, which could provide an antiatherogenic effect greater than that expected from effects on LDL cholesterol and triglycerides alone. However, large, prospective, randomised outcome trials designed for diabetic patients that have studied the efficacy of lipid lowering drug treatment are lacking. The angiographic diabetes atherosclerosis intervention study (DAIS) was the first of the lipid intervention studies specifically designed for diabetes mellitus; fenofibrate resulted in $42 \%$ less increase in stenosis compared with placebo, as assessed by quantitative coronary arteriography. ${ }^{48}$ This was an angiographic study that enrolled 418 diabetic patients and combined those with and without preexisting clinical coronary disease.

The collaborative atorvastatin diabetes study (CARDS) has recently been published. ${ }^{49}$ We excluded this study from our analysis, because it did not fulfil our inclusion criteria (there was no subgroup of non-diabetic patients). However, given the importance of this trial, we did a sensitivity analysis by including

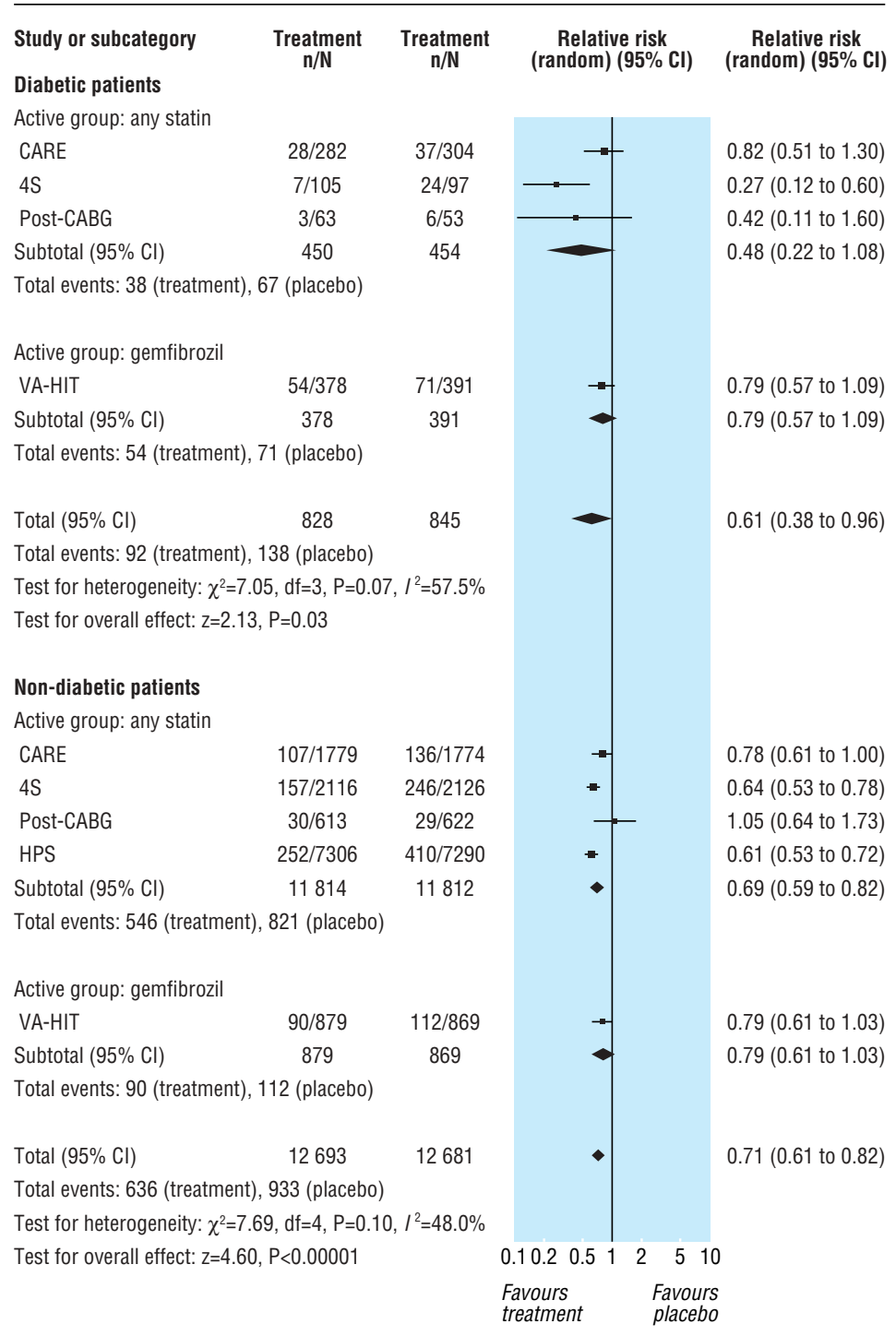

Fig 6 Secondary prevention of non-fatal myocardial infarction 
it in the meta-analysis and found a similar risk reduction for major coronary event in primary prevention for diabetic patients: $23 \%(14 \%$ to $31 \% ; \mathrm{P}<0.00001)$ versus $21 \%(11 \%$ to $30 \% ; \mathrm{P}<0.0001)$ without CARDS. The number needed to treat was the same when we include the results of the CARDS: 37 (25 to 69 ) versus 37 (24 to 75) without CARDS.

Although strong data support the efficacy and safety of statins for primary prevention in patients with diabetes mellitus, some controversy still exists about their use in patients with a low risk of coronary disease..$^{50}$ These ongoing studies will provide the prospective outcome data that are needed for the optimal management of diabetic patients.

Future research should clearly define the threshold over which diabetic patients must be treated and the blood cholesterol target, especially in primary prevention. Until these data are available, we think that our results support the use of statins not only for secondary prevention but also for primary prevention in these patients.

Contributors: JC contributed to the concept and design, data acquisition, data analysis, and interpretation of the data; wrote the first draft of the manuscript; critically revised the manuscript; and gave final approval of the submitted manuscript. MB contributed to the concept and design, data acquisition, and interpretation of data; critically revised the manuscript; and gave final approval of the submitted manuscript. CD contributed to data analysis and interpretation of data, critically revised the manuscript, and gave final approval of the submitted manuscript. AVC contributed to the concept and design and interpretation of the data, critically revised the manuscript, and gave final approval of the submitted manuscript. AVC is the guarantor.

Funding: This was an academic project not funded by any government or non-government grant.

Competing interests: None declared.

Ethical approval: Not needed.

1 Beckman JA, Creager MA, Libby P. Diabetes and atherosclerosis: epidemiology, pathophysiology, and management. JAMA 2002;287:2570-81.

2 Haffner SM, Lehto S, Ronnemaa T, Pyorala K, Laakso M. Mortality from coronary heart disease in subjects with type 2 diabetes and in nondiabetic subjects with and without prior myocardial infarction. N Engl J Med 1998;339:229-34.
3 Miettinen H, Lehto S, Salomaa V, Mahonen M, Niemela M, Haffner SM, et al. Impact of diabetes on mortality after the first myocardial infarction. Diabetes Care 1998;21:69-75. 4 UK Prospective Diabetes Study Group. Effect of intensive blood-glucose control with metformin on complications in overweight patients with type 2 diabetes (UKPDS 34). Lancet 1998;352:854-65.

5 Turner R, Cull C, Holman R. United Kingdom prospective diabetes study 17: a 9-year update of a randomized, controlled trial on the effect of improved metabolic control on complications in non-insulin-dependent diabetes mellitus. Ann Intern Med 1996;124:136-45.

6 Chiquette E, Chilton R. Cardiovascular disease: much more aggressive in patients with type 2 diabetes. Curr Atheroscler Rep 2002:4:134-42.

7 Reaven GM, ChenY-DI, Jeppesen J, Maheux P, Krauss RM. Insulin resistance and hyperinsulinemia in individuals with small, dense, low density lipoprotein particles. J Clin Invest 1993;92:141-6.

8 Austin MA, Edwards KL. Small, dense low density lipoproteins, the insulin resistance syndrome and noninsulin-dependent diabetes. Curr Opin Lipidol 1996;7:167-71.

9 Winkler K, Abletshauser C, Hoffmann MM, Friedrich I, Baumstark MW, Wieland H, et al. Effect of fluvastatin slow-release on low density lipoprotein (LDL) subfractions in patients with type 2 diabetes mellitus: baseline LDL profile determines specific mode of action. J Clin Endocrinol Metab 2002;87:5485-90.

10 Cheung BM, Lauder IJ, Lau CP, Kumana CR. Meta-analysis of large randomized controlled trials to evaluate the impact of statins on cardiovascular outcomes. Br J Clin trolled trials to evaluate the
Pharmacol 2004;57:640-51.

11 Heart Protection Study Collaborative Group. MRC/BHF heart protection study of cholesterol lowering with simvastatin in 20536 high-risk individuals: a randomised placebo-controlled trial. Lancet 2002;360:7-22.

12 Expert Panel on Detection, Evaluation, and Treatment of High Blood Cholesterol in Adults. Executive summary of the third report of the National Cholesterol Education Program (NCEP) expert panel on detection, evaluation, and treatment of high blood cholesterol in adults (Adult Treatment Panel III). JAMA 2001;285:2486-97.

13 Vijan S, Hayward RA. Pharmacologic lipid-lowering therapy in type 2 diabetes mellitus: background paper for the American College of Physicians. Ann Intern Med 2004:140:650-8

14 Snow V, Aronson MD, Hornbake ER, Mottur-Pilson C, Weiss KB. Lipid control in the management of type 2 diabetes mellitus: a clinical practice guideline from the American College of Physicians. Ann Intern Med 2004;140:644-9.

15 Law MR, Wald NJ, Thompson SG. By how much and how quickly does reduction in serum cholesterol concentration lower risk of ischaemic heart disease? $B M J$ 1994:308:367-72.

16 Law MR, Wald NJ, Rudnicka AR. Quantifying effect of statins on low density lipoprotein cholesterol, ischaemic heart disease, and stroke: systematic review and meta-analysis. BMJ 2003;326:1423-7.

17 Fleiss JL. The statistical basis of meta-analysis. Stat Methods Med Res 1993:2:121-45

18 Deeks JJ, Altman DG, Bradburn MJ. Statistical methods for examining heterogeneity and combining results from several studies in meta-analysis. In: Egger M, Davey Smith G, Altman DG, eds. Systematic reviews in health care: meta-analysis in context. 2nd ed. London: BMJ Publication Group, 2001.

19 Smeeth L, Haines A, Ebrahim S. Numbers needed to treat derived from meta-analysis-sometimes informative, usually misleading. BMJ 1999;318:1548-51.

20 Downs JR, Clearfield M, Weis S, Whitney E, Shapiro DR, Beere PA, et al. Primary prevention of acute coronary events with lovastatin in men and women with average cholesterol levels: results of AFCAPS/TexCAPS. JAMA 1998;279:1615-22.

\begin{tabular}{|c|c|c|c|c|c|}
\hline \multirow{3}{*}{$\begin{array}{l}\text { Study or subcategory } \\
\text { Diabetic patients } \\
\text { Active group: any statin }\end{array}$} & \multirow[t]{3}{*}{$\underset{n / \mathbb{N}}{\text { Treatment }}$} & \multirow[t]{3}{*}{$\underset{n / N}{\text { Treatment }}$} & \multirow{2}{*}{\multicolumn{2}{|c|}{$\begin{array}{c}\text { Relative risk } \\
\text { (fixed) }(95 \% \mathrm{Cl})\end{array}$}} & \multirow[t]{3}{*}{$\begin{array}{c}\text { Relative risk } \\
\text { (fixed) }(95 \% \text { Cl) }\end{array}$} \\
\hline & & & & & \\
\hline & & & & & \\
\hline CARE & $76 / 282$ & $116 / 304$ & - & & 0.71 (0.56 to 0.90$)$ \\
\hline $4 \mathrm{~S}$ & 29/251 & 49/232 & $\rightarrow-$ & & 0.55 (0.36 to 0.84$)$ \\
\hline Post-CABG & $7 / 63$ & $7 / 53$ & - & & 0.84 (0.32 to 2.25$)$ \\
\hline LIPID & $75 / 542$ & $97 / 535$ & $=$ & & 0.76 (0.58 to 1.01$)$ \\
\hline Total $(95 \% \mathrm{Cl})$ & 1138 & 1124 & - & & 0.70 (0.59 to 0.83$)$ \\
\hline \multicolumn{6}{|c|}{ Total events: 187 (treatment), 269 (placebo) } \\
\hline \multicolumn{6}{|c|}{ Test for heterogeneity: $\chi^{2}=1.82, d f=3, P=0.61, l^{2}=0 \%$} \\
\hline \multicolumn{6}{|c|}{ Test for overall effect: $z=4.23, P<0.0001$} \\
\hline \multicolumn{6}{|l|}{ Non-diabetic patients } \\
\hline \multicolumn{6}{|l|}{ Active group: any statin } \\
\hline CARE & $275 / 1779$ & $349 / 1774$ & $=$ & & 0.79 (0.68 to 0.91$)$ \\
\hline $4 \mathrm{~S}$ & 220/1949 & $327 / 1966$ & - & & 0.68 (0.58 to 0.80$)$ \\
\hline Post-CABG & $43 / 613$ & 61/622 & $\rightarrow$ & & $0.72(0.49$ to 1.04$)$ \\
\hline HPS & 679/7306 & $896 / 7290$ & - & & 0.76 (0.69 to 0.83 ) \\
\hline LIPID & $510 / 3970$ & $611 / 3967$ & - & & 0.83 (0.75 to 0.93$)$ \\
\hline Total $(95 \% \mathrm{Cl})$ & 15617 & 15619 & - & & 0.77 (0.73 to 0.82$)$ \\
\hline \multicolumn{6}{|c|}{ Total events: 1727 (treatment), 2244 (placebo) } \\
\hline \multicolumn{6}{|c|}{ Test for heterogeneity: $\chi^{2}=4.86, \mathrm{df}=4, \mathrm{P}=0.30, I^{2}=17.6 \%$} \\
\hline \multirow{2}{*}{\multicolumn{3}{|c|}{ Test for overall effect: $z=8.77, P<0.00001$}} & 0.10 .20 .51 & 2510 & \\
\hline & & & $\begin{array}{l}\text { Favours } \\
\text { treatment }\end{array}$ & $\begin{array}{l}\text { Favours } \\
\text { placebo }\end{array}$ & \\
\hline
\end{tabular}

Fig 7 Secondary prevention of myocardial revascularisation procedures (coronary artery bypass grafting or percutaneous transluminal coronary angioplasty) 
Research

\begin{tabular}{|c|c|c|c|c|c|c|c|c|c|}
\hline \multirow[b]{2}{*}{ Outcome } & \multicolumn{3}{|c|}{ Diabetic patients } & \multicolumn{3}{|c|}{ Non-diabetic patients } & \multicolumn{3}{|c|}{ All patients } \\
\hline & NNT & Benefit/1000 & $\begin{array}{c}\text { Weighted } \\
\text { follow-up } \\
\text { average } \\
\text { (years) }\end{array}$ & NNT & Benefit/1000 & $\begin{array}{l}\text { Weighted } \\
\text { follow-up } \\
\text { average } \\
\text { (years) }\end{array}$ & NNT & Benefit/1000 & $\begin{array}{c}\text { Weighted } \\
\text { follow-up average } \\
\text { (years) }\end{array}$ \\
\hline \multicolumn{10}{|l|}{ Primary prevention } \\
\hline Major coronary event & 37 (24 to 75) & 27 & 4.5 & 47 (35 to 73 ) & 21 & 4.3 & 44 (33 to 64) & 23 & 4.4 \\
\hline \multicolumn{10}{|l|}{ Secondary prevention } \\
\hline Major coronary event & 15 (11 to 24$)$ & 67 & 5.1 & 17 (14 to 20$)$ & 59 & 5.1 & 16 (14 to 19) & 63 & 5.1 \\
\hline CHD death or non-fatal MI & 15 (9 to 40$)$ & 67 & 5.0 & 21 (17 to 27) & 48 & 5.0 & 21 (17 to 26$)$ & 48 & 5.0 \\
\hline CHD death & 19 (10 to 90$)$ & 53 & 5.0 & 61 (31 to 318$)$ & 16 & 5.0 & 54 (36 to 90$)$ & 19 & 5.0 \\
\hline Non-fatal MI & 11 (5 to 141$)$ & 91 & 5.0 & 34 (23 to 60$)$ & 29 & 5.0 & 31 (21 to 56$)$ & 32 & 5.0 \\
\hline Revascularisation & 11 (8 to 21$)$ & 91 & 5.6 & 25 (20 to 32$)$ & 40 & 5.3 & 23 (18 to 29) & 43 & 5.3 \\
\hline Stroke & 19 (11 to 50$)$ & 53 & 5.5 & 84 (53 to 157) & 12 & 5.3 & 66 (47 to 106$)$ & 15 & 5.3 \\
\hline
\end{tabular}

$\mathrm{CHD}=$ coronary heart disease; $\mathrm{Ml}=$ myocardial infarction; $\mathrm{NNT}=$ number needed to treat.

21 ALLHAT Officers and Coordinators for the ALLHAT Collaborative Research Group. Major outcomes in moderately hypercholesterolemic, hypertensive patients randomized to pravastatin vs usual care: the antihypertensive and lipid-lowering treatment to prevent heart attack trial (ALLHAT-LLT). JAMA 2002;288:2998-3007.

22 Frick MH, Elo O, Haapa K, Heinonen OP, Heinsalmi P, Helo P, et al. Helsinki heart study: primary-prevention trial with gemfibrozil in middle-aged men with dyslipidemia. Safety of treatment, changes in risk factors, and incidence of coronary heart disease. $N$ Engl J Med 1987;317:1237-45.
23 Sever PS, Dahlöf B, Poulter NR, Wedel H, Beevers DG, Caulfield M, et al. Prevention of coronary and stroke events with atorvastatin in hypertensive patients who have average or lower-than-average cholesterol concentrations, in the Anglo-Scandinavian cardiac outcomes trial-lipid lowering arm (ASCOT-LLA): a multicentre randomised controlled trial. Lancet 2003;361:1149-58.

24 Collins R, Armitage J, Parish S, Sleight P, Peto R, Heart Protection Study Collaborative Group. MRC/BHF heart protection study of cholesterol-lowering with simvastatin in

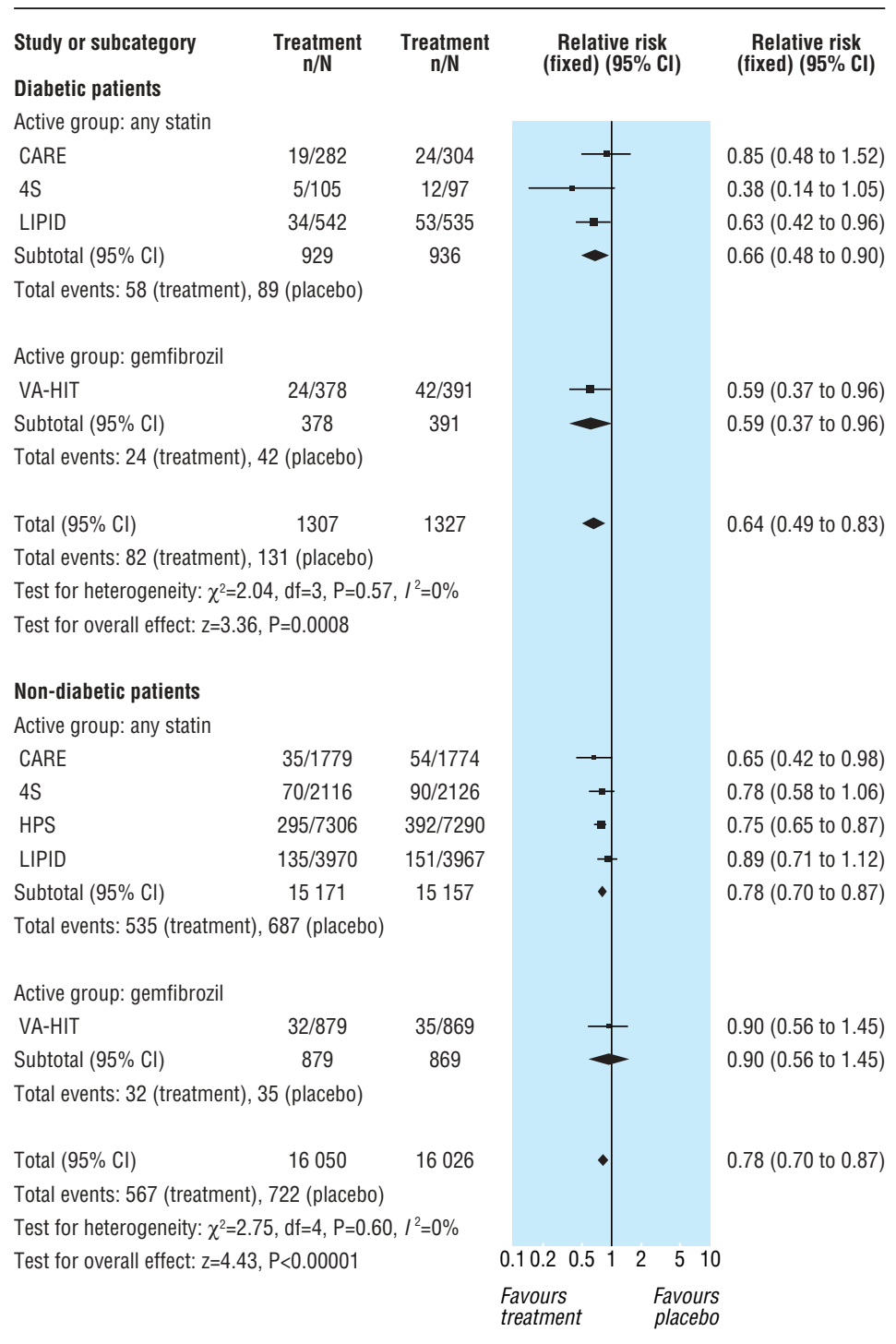

Fig 8 Secondary prevention of stroke 


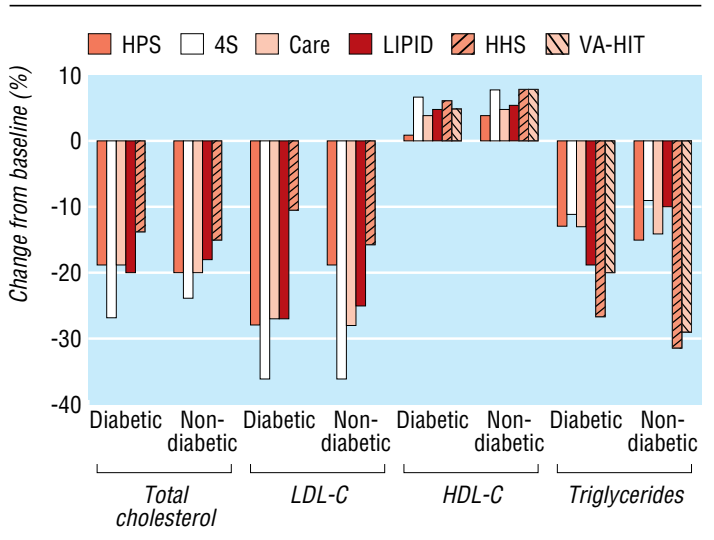

Fig 9 Change in blood lipid concentrations. HDL-C=high density lipoprotein cholesterol; LDL-C=low density lipoprotein cholesterol (no data for total cholesterol were available in VA-HIT)

5963 people with diabetes: a randomised placebo-controlled trial. Lancet 2003;361:2005-16.

25 Shepherd J, Blauw GJ, Murphy MB, Cobbe SM, Bollen EL, Buckley BM, et al. Pravastatin in elderly individuals at risk of vascular disease (PROSPER): a randomised controlled trial. Lancet 2002;360:1623-30.

26 Pyorala K, Pedersen TR, Kjekshus J, Faergeman O, Olsson AG, Thorgeirsson G. Cholesterol lowering with simvastatin improves prognosis of diabetic patients with coronary heart disease: a subgroup analysis of the Scandinavian simvastatin survival study (4S). Diabetes Care 1997;20:614-20.

27 Haffner SM, Alexander CM, Cook TJ, Boccuzzi SJ, Musliner TA, Pedersen TR, et al. Reduced coronary events in simvastatin-treated patients with coronary heart disease and diabetes or impaired fasting glucose levels: subgroup analyses in the Scandinavian simvastatin survival study. Arch Intern Med 1999;159:2661-7.

28 Scandinavian Simvastatin Survival Study Group. Randomised trial of cholesterol lowering in 4444 patients with coronary heart disease: the Scandinavian simvastatin survival study (4S). Lancet 1994;344:1383-9.

29 Sacks FM, Pfeffer M, Moye LA, Rouleau JL, Rutherford JD, Cole TG, et al. The effect of pravastatin on coronary events after myocardial infarction in patients with average cholesterol levels. $N$ Engl J Med 1996;335:1001-9.

30 Goldberg RB, Mellies MJ, Sacks FM, Moye LA, Howard BV, Howard WJ, et al. Cardiovascular events and their reduction with pravastatin in diabetic and glucose-intolerant myocardial infarction survivors with average cholesterol levels: subgroup analyses in myocardial infarction survivors with average cholesterol levels: subgroup ana
the cholesterol and recurrent events (CARE) trial. Circulation 1998;98:2513-9.

31 The Long-Term Intervention with Pravastatin in Ischaemic Disease (LIPID) Study Group. Prevention of cardiovascular events and death with pravastatin in patients with coronary heart disease and a broad range of initial cholesterol levels. N Engl J Med 1998;339:1349-57

\section{What is already known on this topic}

Cardiovascular disease is the most common cause of death in the general population and causes even greater morbidity and mortality in people with type 2 diabetes

The effectiveness of lipid lowering drugs in reducing the risk of coronary events has been shown in large scale studies of both primary and secondary prevention

Large randomised outcome trials designed specifically for diabetic patients are lacking

\section{What this study adds}

Meta-analysis of published trials showed that patients with diabetes benefit more than non-diabetic patients, in both primary and secondary prevention

This may have important clinical implications, particularly for primary prevention in patients with type 2 diabetes
32 Keech A, Colquhoun D, Best J, Kirby A, Simes RJ, Hunt D, et al. Secondary prevention of cardiovascular events with long-term pravastatin in patients with diabetes or impaired fasting glucose: results from the LIPID trial. Diabetes Care 2005;26:2713-21.

33 Serruys PW, de Feyter P, Macaya C, Kokott N, Puel J, Vrolix M, et al. Fluvastatin for prevention of cardiac events following successful first percutaneous coronary intervention: a randomized controlled trial. JAMA 2002;287:3215-22

34 Post Coronary Artery Bypass Graft Trial Investigators. The effect of aggressive lowering of low-density lipoprotein cholesterol levels and low-dose anticoagulation on obstructive changes in saphenous-vein coronary-artery bypass grafts. N Engl J Med 1997;336:153-62.

35 Hoogwerf BJ, Waness A, Cressman M, Canner J, Campeau L, Domanski M, et al. Effects of aggressive cholesterol lowering and low-dose anticoagulation on clinical and of aggressive cholesterol lowering and low-dose anticoagulation on clinical and
angiographic outcomes in patients with diabetes: the post coronary artery bypass graft angiographic outcomes in pati

36 Rubins HB, Robins SJ, Collins D, Fye CL, Anderson JW, Elam MB, et al. Gemfibrozil for the secondary prevention of coronary heart disease in men with low levels of high-density lipoprotein cholesterol. N Engl J Med 1999;341:410-8.

37 Rubins HB, Robins SJ, Collins D, Nelson DB, Elam MB, Schaefer EJ, et al. Diabetes, plasma insulin, and cardiovascular disease: subgroup analysis from the Department of Veterans Affairs high-density lipoprotein intervention trial (VA-HIT). Arch Intern Med 2002;162:2597-604.

38 Shepherd J, Cobbe SM, Ford I, Isles CG, Lorimer AR, Macfarlane PW, et al. Prevention of coronary heart disease with pravastatin in men with hypercholesterolemia. $N$ EnglJ Med 1995;333:1301-7.

39 Freeman DJ, Norrie J, Sattar N, Neely RD, Cobbe SM, Ford I, et al. Pravastatin and the development of diabetes mellitus: evidence for a protective treatment effect in the west of Scotland coronary prevention study. Circulation 2001;103:357-62.

40 The BIP Study Group. Secondary prevention by raising HDL cholesterol and reducing triglycerides in patients with coronary artery disease: the bezafibrate infarction prevention (BIP) study. Circulation 2000;102:21-7.

41 Verschuren WM, Jacobs DR, Bloemberg BP, Kromhout D, Menotti A, Aravanis C, et al. Serum total cholesterol and long-term coronary heart disease mortality in different cultures: twenty-five-year follow-up of the seven countries study. JAMA 1995;274:131-6.

42 Neaton JD, Blackburn H, Jacobs D, Kuller L, Lee DJ, Sherwin R, et al. Serum cholesterol level and mortality findings for men screened in the multiple risk factor intervention trial. Arch Intern Med 1992;152:1490-500.

43 Chen Z, Peto R, Collins R, MacMahon S, Lu J, Li W. Serum cholesterol concentration and coronary heart disease in population with low cholesterol concentrations. BMJ 1991:303:276-82.

44 Ramsay LE, Haq IU, Jackson PR, Yeo WW, Pickin DM, Payne JN. Targeting lipid-lowering drug therapy for primary prevention of coronary disease: an updated Sheffield table. Lancet 1996;348:387-8.

45 Diabetes mellitus: a major risk factor for cardiovascular disease. A joint editorial statement by the American Diabetes Association; the National Heart, Lung, and Blood Institute; the Juvenile Diabetes Foundation International; the National Institute of Diabetes and Digestive and Kidney Diseases; and the American Heart Association. Circulation 1999;100:1132-3.

46 Stamler J, Vaccaro O, Neaton JD, Wentworth D. Diabetes, other risk factors, and 12-yr cardiovascular mortality for men screened in the multiple risk factor intervention trial. cardiovascular mortality for $\mathrm{m}$

47 Ko DT, Mamdani M, Alter DA. Lipid-lowering therapy with statins in high-risk elderly patients: the treatment-risk paradox. JAMA 2004;291:1864-70.

48 Effect of fenofibrate on progression of coronary-artery disease in type 2 diabetes: the diabetes atherosclerosis intervention study, a randomised study. Lancet 2001;357:90510 .

49 Colhoun HM, Betteridge DJ, Durrington PN, Hitman GA, Neil NA, Livingstone SJ, et al. Primary prevention of cardiovascular disease with atorvastatin in type 2 diabetes in the collaborative atorvastatin diabetes study (CARDS): multicentre randomised placebo-controlled trial. Lancet 2004:364:685-96.

50 Garg A. Statins for all patients with type 2 diabetes: not so soon. Lancet 2004;364:641-2. (Accepted 23 February 2006)

doi 10.1136/bmj.38793.468449.AE

Center for Evidence-Based Medicine, University of Lisbon School of Medicine, Lisbon, Portugal

João Costa assistant in clinical pharmacology and therapeutics

Margarida Borges clinical consultant in pmeumology

António Vaz Carneiro clinical professor of medicine

Department of Cardiology, Santa Maria University Hospital, Lisbon Cláudio David assistant in clinical pharmacology and therapeutics

Correspondence to: A V Carneiro, Faculdade de Medicina de Lisboa, CEMBE, Piso 6, Av Prof Egas Moniz., 1649-028 Lisboa, Portugal avc@fm.ul.pt

\section{Amendment}

This is version 2 of the paper. Table 1 has minor changes, and the graphics in figure 2 have been revised to accord with the numbers given. These changes do not alter the conclusions of the article. 